\title{
El cine histórico de Hollywood como acción hegemónica
}

Fabio Gabriel Nigra*

Resumen: El presente texto es un avance de un trabajo mayor, que se reflexiona sobre la particular narrativa fílmica de las películas históricas emanadas desde los Grandes Estudios de Hollywood. Por ello se presentan al inicio las más importantes líneas teóricas, como Ferro y Rosenstone, para luego establecer la propia postura. En segundo lugar, se plantea la fórmula historiográfica y fílmica que caracteriza a dichos filmes, y se presentan ejemplos. La conclusión a la que se arriba permite demostrar que la gran mayoría de dichas producciones tienen su basamento en cuestiones culturales e ideológicas que no solamente garantizan el éxito comercial; también refuerzan principios ideológicos funcionales a la clase dominante. Palabras clave: Estados Unidos. Cine-Historia. Hegemonía.

\section{Introducción}

El cine es un arte que incorpora múltiples lenguajes y dimensiones. Así que, y tal como sostienen importantes estudiosos del tema, desde comienzos del siglo XX pudo actuar como una verdadera herramienta de reproducción ideológica. Esto lo vemos en el cine de la Unión Soviética, el norteamericano, y el nazi en la primera mitad del siglo XX, entre otros casos. En estos ejemplos se advierte la importancia del cinematógrafo como hecho social, en particular para la construcción de las representaciones imaginarias del mundo, vistas a través del lente de la cámara. Asimismo, el cine comercial es un medio de comunicación masivo que muestra en gran medida

"Doutor em História, professor de História dos Estados Unidos da Universidade de Buenos Aires (UBA). E-mail: fabio.nigra@speedy.com.ar

Anos 90, Porto Alegre, v. 22, n. 42, p. 375-405, dez. 2015 
una perspectiva favorable al poder, perspectiva en la que el espectador, usualmente desprevenido, suele participar en forma acrítica.

Por esta razón es tan importante el estudio de este fenómeno teniendo en cuenta que su supuesta perspectiva inocente no es tan así, que la transparencia de su presentación es un fenómeno detalladamente concebido, y que existen particularidades ideológicas en la elaboración de lashistorias, máxime si estas historias refieren al pasado, a la Historia. En consecuencia trabajar en esta dirección resulta relevante desde el momento en que dichas imágenes y visiones son las que finalmente quedan instaladas, para los espectadores comunes, como la "verdad histórica", sin tomarse en consideración el hecho de que en la mayor parte de los casos el asesoramiento técnico histórico se subordina a las necesidades de la taquilla. En otras palabras, el cine - como medio de comunicación masivo - puede "inventar" un hecho que se transformará en la percepción de los espectadores en la historia real, lo que realmente sucedió; y hasta la posibilidad de contar ese hecho que previamente no tenía necesariamente peso en el registro histórico del ciudadano común, como puede interpretarse de películas tales como Corazón Valiente ${ }^{1}$ o La noche de los lápices ${ }^{2}$. Además, debe tenerse en cuenta que muchos de estos filmes son utilizados en distintos niveles educativos como forma de transmisión de conocimiento histórico, y en más de una ocasión sin tomar los recaudos críticos imprescindibles.

La industria cinematográfica norteamericana es uno de los más poderosos aparatos político-ideológicos del planeta (SANCHEZ RUIZ, 2003; AUGROS, 2000; MILLER et al., 2005; GONZALEZ PASCUAL, 2010), y gracias a ello tiene una forma propia de observar y contar su propio pasado con objetivos previamente determinados. Es por ello que nos planteamos reflexionar sobre esta particular fórmula historiográfica y discursiva, con la pretensión de destacar algunos elementos a tener en cuenta al momento de formular cualquier tipo de análisis crítico. Aunque cada film puede y debe ser visto como una fuente del momento en que es producido, recorrer las visiones del pasado y de hacer historia de Estados Unidos de América por la acaudalada Hollywood nos acerca a una mirada historiográfica más vinculada a los poderes político-económicos que han construido el aparato ideológico de la hegemonía norteamericana, 
como por caso puede verse con total claridad en filmes tales como La Conquista del Oeste ${ }^{3}$, donde se trabaja una reproducción casi mecánica de las tesis de Turner sobre la frontera, reforzando así una perspectiva elaborada como constructo ideológico de fines del siglo XIX, a fin de incorporar un pasado que se enfrentaba al masivo fenómeno de la inmigración (NIGRA, 2012, p. 85-102). Para ello los Grandes Estudios de Hollywood y los sucesivos gobiernos de Estados Unidos han labrado una relación profunda (ROBB, 2006), de forma tal que se ha podido construir una mirada consensual del pasado, con efectos didácticos al interior del país y también hacia el exterior.

Por ello analizaremos en primer lugar los planteos teóricos más importantes, junto a nuestra postura; luego, se trabajarán las vinculaciones existentes entre discursos, esto es, el del cinematógrafo operando sobre el de la Historia y cómo se construye un consenso gracias a la reutilización de un discurso histórico específico, junto a un conjunto de elementos que aparecen como substrato recurrente en los films históricos. Finalmente, se aplicarán muchos de los principios en ejemplos concretos.

En lo que hace a la reflexión sobre el fenómeno de la representación de la Historia en el Cine, se ubican investigadores que han marcado claramente dos líneas de trabajo e interpretación. En un lado se encuentra la que ha trazado Marc Ferro, historiador francés de la Escuela de los Annales, quien entiende que una película histórica habla más de la época en que fue concebida y filmada que de la etapa histórica que busca representar, al encontrarse profundamente condicionada por los entrecruzamientos ideológicos de una sociedad dada. De esta forma, para este autor "la aportación del cine a la inteligibilidad de los fenómenos históricos varía, pues, según su grado de autonomía del autor y su contribución estética" (FERRO, 1995, p. 194). En suma, Ferro plantea la posibilidad del uso del cine en el estudio de la historia teniendo en cuenta que las películas de una manera u otra son parte del acervo histórico y 
cultural de la sociedad en que son generadas, y por ello dicen más de su propia época que lo que quieren contar sobre el pasado. Es para destacar que en América Latina este autor ha tenido un importante nivel de penetración y relevancia, tal como puede observarse de los estudios efectuados por Jorge Nóvoa y José D’Assuncao Barros - y sus seguidores en la Oficina de Cine e Historia de la Universidad Federal de Bahía, Brasil; o los desarrollos de Félix J. Lozano Cárdenas y María I. Mendoza Bernal en la Facultad Experimental de Ciencias, perteneciente al Departamento de Ciencias Humanas de la Universidad del Zulía, Maracaibo, como así también los de Emperatiz Arreaza en Facultad de Humanidades y Educación, Centro de Estudios Históricos, de la Universidad del Zúlia, Maracaibo, Venezuela, por ejemplo.

Por el otro lado se encuentra la posición de Robert Rosenstone ${ }^{4}$, historiador norteamericano que desarrolla su trabajo en el California Institute of Technology, que plantea que el cine es una herramienta importante como mecanismo de narración de la historia. Asumiendo que es una nueva manera de contar el pasado - como en su época lo fue la tradición oral al estilo de Heródoto -, y que "la historia filmada siempre será una reflexión sobre el pasado más personal que la que plantee un trabajo escrito" (ROSENSTONE, 1997, p. 56), este historiador sostiene que al vivir en una época posliteraria "[...] sin denigrar el poder de la palabra se debe defender la capacidad de reconstrucción de otros medios", como en este caso es el cine histórico. Sin embargo, para ser considerado histórico, un film debe ocuparse "[...] de los temas, las ideas y los razonamientos del discurso histórico” (Ibid., p. 59).

Robert Rosenstone ha hecho una opción ideológica fuerte por la construcción narrativa postmoderna, con el argumento de que la Historia cinematográfica es plausible porque no se lee, en una época en que el texto y su lectura se encuentran en retirada. De esta forma ha abogado por la búsqueda de un camino de síntesis entre la interpretación postmoderna de la Historia - con amplias referencias al trabajo señero de Hayden White (1992), en el que la escritura de la Historia es una narración como cualquier otra ${ }^{5}$-, y el lenguaje del cine que elabora una narración sin seguir pautas específicas de la academia histórica. 
En su visión, Hollywood ha tratado de construir una historicidad que este autor ha denominado "falsa" o "mito del realismo", donde pareciera ser que lo importante es la reproducción objetística del pasado, esto es, la idea - tal vez errónea - de que la historia es en verdad nada más que "un retrato de un período", puesto que los objetos son historia en sí mismos. De esta forma, dice, Hollywood cree que si hace una reproducción de los escenarios y los vestuarios del pasado muy exactos, está haciendo historia.

La Historia, asume Rosenstone como un inicio analítico, es una construcción efectuada por hombres (historiadores) en el intento de dar sentido al pasado, ya que ni la gente ni las naciones viven "relatos históricos"; asimismo, los relatos elaborados por los historiadores son, en su forma de ver, "ficciones narrativas", o sea, una recreación del pasado, no el pasado en sí; además, en el discurso narrativo, la realidad histórica está condicionada por las convenciones en la forma de escribir, amén del punto de vista que el historiador haya seleccionado; por último, el lenguaje nunca es aséptico, y por ende no se puede gracias a él representar el pasado tal cual fue, "todo lo contrario, el lenguaje crea, estructura la historia y la imbuye de un significado" dice, sosteniéndose en White (ROSENSTONE, 1997, p. 36).

El autor sostiene que "[...] la historia como relato dramático en imágenes se apoya en la invención tanto de pequeños detalles como de hechos importantes" (ROSENSTONE, 1997, p. 57). La diferencia entre la ficción y la Historia, entonces, es que si bien las dos narran alguna historia, la de la primera es verosímil al apoyarse en las fuentes, y porque la filmación de la totalidad del hecho histórico es imposible. La ficción nos permite seleccionar y sintetizar acontecimientos y marcar, con ellos, procesos que denomina condensación (Ibid., p. 58). Entonces, si se acepta que las narraciones escritas son "ficciones narrativas", las narraciones visuales, dice, deben ser consideradas "ficciones visuales", es decir, representaciones tan reales del pasado como los libros (Ibid., p. 36). Estas representaciones deben tener normas, tal como la escritura científica de la historia, pero deberían ser normas en consonancia con las posibilidades del medio de transmisión: "Es imposible juzgar una película histórica con las normas que rigen un texto". 
Entonces plantea en forma de síntesis los ejes que guían su esfuerzo: "Mi trabajo no se ha orientado a criticar, sino a evaluar las posibilidades de los films históricos; a tratar de entender, desde su misma perspectiva, cómo un realizador puede plasmar el pasado en imágenes. Situarse en dicha posición puede ser arriesgado para el académico. Implica una complicidad, una identificación, que conducen a una reflexión lógica y herética a un tiempo: la misma naturaleza de los medios audiovisuales nos fuerza a redefinir y/o ampliar el significado del concepto de historia” (Ibid., p. 16-17).

Sin embargo, y sin perjuicio de que su aporte ha resultado clave en la dirección propuesta, no nos permite elaborar pautas claras y definitivas sobre el problema de la narración, porque tanto en la escritura como en la filmación el soporte sustancial es el lenguaje. Debemos tener en cuenta que, tal como la mayoría de los analistas y estudiosos del cine sostienen, existe un modelo de cine clásico de Hollywood, que pretende borrar en el filme las marcas de su existencia, de su construcción. Es una manera de narrar con técnicas específicas y muy codificadas, que elaboraron un lenguaje particular. Gracias a él se pretende dar la idea de que la historia se cuenta por sí misma sin intermediarios, buscando lograr que el espectador participe, pero como un voyeur. El carácter de hechos ocurridos, dice Monterde, "[...] no es garantía de verdad, sino que solo forma parte de una estrategia de la representación” (MONTERDE, 1986, p. 92). Es como si el cine solamente se propusiera estar ahí, ante la realidad, para permitirle llegar hasta nosotros a través del objetivo de la cámara. De esta forma, "[...] su verdad dependerá de la verdad de lo que exista ante la cámara, pues en principio la misma solo está obligada a restituir ese 'ponerse ante la cámara' como todo testimonio de su existencia" (MONTERDE, 1986, p. 93). Y por ello esta apariencia de verdad le permite enmascarar que el relato es arbitrario, que la narración es intervenida como una construcción y que la sucesión de acciones tienen pautas específicamente elaboradas para su encadenamiento (AUMONT; BERGALA; MARIE; VERNET, 2011, p. 121).

El modelo de cine de Hollywood, llamado "clásico", tiene un conjunto de ventajas que lo asemejan a la escritura tradicional de la Historia, tal como sostiene Monterde: "El placer obtenido de una película de ficción surge de una mezcla de historia y de 
discurso, en la que el espectador ingenuo (que uno sigue siendo) y el conocedor encuentran al mismo tiempo, con una muy ligera superación, motivo para estar satisfechos. El cine clásico obtiene de ahí su eficacia. A través de una regulación a la vez tenue y fuerte, la institución cinematográfica gana en los dos campos: si el espectador se desliza por y en la historia, aquella se le impone subrepticiamente; si atiende al discurso, es glorificada por su savoirfaire (MONTERDE, 1986, p. 122).

En la misma dirección que Monterde argumenta Ismail Xavier, cuando plantea que lo que él llama el naturalismo refiere a la construcción de un espacio narrativo fílmico que busca una reproducción fiel de las apariencias inmediatas del mundo físico, y a la interpretación de los actores que plantean una reproducción del comportamiento humano, con reacciones "naturales". El principio que está por detrás de esta operación es "el establecimiento de la ilusión de que los espectadores están en contacto directo con el mundo representado, sin mediaciones, como si todos los aparatos de lenguaje utilizados constituyesen un dispositivo transparente (el discurso como naturaleza)" (XAVIER, 2008, p. 56). De esta forma, para Xavier, la representación es discurso y es retórica. Tal como sostiene respecto a los films históricos,

[...] esa reproducción, dirigida hacia un evento natural o a la arquitectura, decoración, vestuario y "acontecimientos" de un determinado período histórico, funciona como instrumento retórico. La "seriedad" de la reconstrucción y el esmerado cuidado que se manifiesta en los detalles simbolizan una actitud de "respeto a la verdad" que tiende a ser aceptada para el filme en su totalidad” (XAVIER, 2008, p. 57).

Concluye, entonces, que esta construcción finamente elaborada por Hollywood tiene la pretensión de afirmar "discurso = verdad" (Ibid., loc. cit.). Pero puede irse más allá, ya que la misma realidad no es un dato que se nos aparece como algo inexorable. La realidad se encuentra condicionada por la producción social de sentido tal como la plantea Eliseo Verón (VERON, 1998). 
No es por casualidad, entonces, que el cine clásico de Hollywood replica los artilugios exitosos de la narración histórica positivista, pero efectuando operaciones mucho más complejas que las que a simple vista aparecen.

\section{II}

Para cualquier ciudadano común la Historia es entendida como esa narración que cuenta las batallas, los actos heroicos de los grandes personajes patrios, las fechas que no deben ser olvidadas... algo muy aburrido en verdad, sin perjuicio de que en la actualidad existen muchos historiadores que siguen trabajando en la que podríamos llamar la forma tradicional (del siglo XIX). En la escuela es una de las materias más tediosas para la mayoría de los estudiantes, y cualquier persona que se encuentra con un historiador en una fiesta familiar le pide que le recomiende algún libro de historia que diga "la verdad". Todo lo dicho en las líneas precedentes es una constante derivada del modelo positivista de hacer historia: la Historia bien hecha dice la verdad de lo que pasó; en la escuela, el aburrimiento es culpa de los docentes y no de la forma hegemónica de transmitirla.

Y sin embargo, el mismo hecho histórico contado en una película actúa necesariamente en la percepción de los espectadores medios como la verdad de lo que pasó y - desde ya -, no es percibido como algo tedioso, en tanto el producto "film" no sea soporífero.

Recordemos brevemente que el positivismo historicista se basaba en el análisis de las fuentes que eran principalmente documentos escritos, y la escritura como narración de los hechos constatados. Sea en la versión historicista de tipo alemana, como la más positivista de mediados a fines del siglo XIX, la narración de los hechos humanos pretendía conceder a las ideas y valores de los grandes hombres el lugar central de su reflexión. El supuesto problema para el cine histórico lo marcó en su oportunidad Robert Rosenstone: "Muchas películas 'históricas' han seguido el ejemplo de Hollywood, donde la historia se reduce a un drama histórico, un relato de pasión o aventuras en un pasado lejano y atrayente" 
(ROSENSTONE, 1997, p. 18); es decir, las películas tienden a destacar a los individuos en detrimento de los grupos o el proceso general, donde el film tradicional - al que aquí denominamos de "narración clásica" - nos explica la historia como

[...] un principio, un desarrollo y un final. Este relato lleva implícito un mensaje moral, por lo general optimista, que está impregnado de una concepción de la historia que se articula en términos de progreso, incluso en el caso de que se suscriban las teorías marxistas... no importa cuál sea el tema que trate el film histórico - el esclavismo, el Holocausto o los jemeres rojos -, la conclusión es casi siempre la misma: la humanidad mejora y/o ha mejorado” (Ibid., p. 50).

Finalmente, este tipo de películas explica la historia mediante los avatares de individuos que son importantes porque la cámara ha decidido que así sea. Estos son gente normal - por lo general, aclaremos, no debe descartarse que también se presentan películas de héroes que forman parte del panteón nacional o que pertenecen a la historia universal -, que han realizado actos heroicos o admirables, o que han sufrido la explotación u opresión y que la solución de sus inconvenientes tiende a sustituir la de los problemas generales. Por ello, "[...] la personificación se convierte en un mecanismo para no tratar los problemas sociales, a menudo sin solución, que plantea el film" (Ibid., p. 50-51). Esto se constata en un conjunto de ideas recurrentes en los films, que han dado en llamarse invariantes (concepto que se desarrollará más adelante) (NIGRA, 2007).

Siguiendo lo postulado por David Carr, las representaciones narrativas de la realidad histórica pueden considerarse realistas y veraces "pues los agentes humanos habitan un mundo sociocultural que está estructurado narrativísticamente", entonces sostiene la idea de que los historiadores no imponen una forma narrativa a los acontecimientos, sino que descubren la historia real vivida, en la que dichos elementos son constitutivos (WHITE, 2011, p. 481). Es esta última una hipótesis muy contundente - más que nada, el concepto de descubrimiento -, y por lo menos corresponde matizarla con la idea de que muchos historiadores (y en particular, divulgadores de 
Historia) construyen una representación del pasado estructurada narrativísticamente, que en última instancia es una forma de acceso razonable para los no especialistas. Por ello, la narración que se encuentra en un film debe seguir pautas que permitan la articulación mental concreta de los espectadores, de la misma manera en que se forman los esquemas mentales descriptos por Bordwell (BORDWELL, 1996).

Entonces, si se asume tal como explicara magistralmente Collingwood, que el positivismo construía sus historias narrativas apoyándose en el método inductivo (COLLINGWOOD, 2001, p. 199 et seq.), no es sorprendente que la narración clásica de Hollywood se sostenga también en el método inductivo. Nótese que el mecanismo fílmico permite ir presentando elementos que avanzan de lo particular a lo general, de forma tal que el guión se estructura poniendo un hecho tras otro para garantizar que la historia avance (BORDWELL, 1996). De similar manera, el positivismo toma la fórmula de la causalidad para encadenar los hechos dejando, si se quiere, el camino allanado para un guionista que maneja aceitadamenteel formato estructural (el de la narración fílmica y el de la Historia), no tenga mucho trabajo para poner las cosas en fila.

El espectador - en particular el estadounidense - ya posee su biblioteca de esquemas, lo que va a esperar ver, apoyado en un conjunto de situaciones que se reproducen en la inmensa mayoría de las versiones históricas elaboradas a la manera clásica, que son los llamados invariantes: el primero es el de la frontera, concepto decimonónico elaborado por Frederick J. Turner en 1898 y gracias al cual los norteamericanos asumen que su sistema político se fundamenta en la lucha de los hombres y mujeres contra el medio natural y los indios, y por ello es único y completamente diferente al modelo democrático europeo. Escribió Turner que:

[...] hasta hoy, la historia norteamericana ha sido sobre todo la de la colonización del Gran Oeste. La existencia de una zona de tierras libres... explican el desenvolvimiento de la nación... Las peculiaridades de las instituciones norteamericanas radican en el hecho de que se han visto obligadas a adaptarse a los cambios de un pueblo en expansión (TURNER, 1961, p. 21). 
Con esta base ideológica - que obviamente es mucho más compleja y con puntualizaciones específicas -, películas tales como La conquista del Oeste o Pasaje al Noroeste ${ }^{6}$ resultan formadoras de ideología, por cuanto le dice al espectador norteamericano qué es lo que tienen que pensar sobre su pasado, por un lado, como si fuera un manual de primaria; pero, por otro, dichos filmes lanzan mensajes subterráneos, en los que, por ejemplo, un simple granjero abandonó el este pedregoso y, a través y gracias a la canalización del lago Erie, se pudo mudar al oeste a iniciar una nueva vida. El hombre común, el haber nacido en una "cabaña de madera", expresa el ideal de simpleza con el que cualquier norteamericano se enorgullece. Las películas indicadas, como muchas otras, construyen una visión específica del pasado, que se sostienen indudablemente en el desarrollo que pudo poner en palabras el estudio de Turner. Por eso este autor ha sido un referente clave en la construcción de un pasado que, es evidente, no se corresponde con mucho de lo que pasó, ya que este pasado resulta funcional a las necesidades de una clase dominante mucho más refinada y compleja que lo que se quiere transmitir como valores e ideales de lo norteamericano.

El segundo invariante es el excepcionalismo. Puede verse en la mayor parte de las películas que tratan sobre aspectos históricos o socio-históricos, que los norteamericanos se creen diferentes al resto del mundo occidental, gracias a lo aprendido en la dura lucha de la frontera. De esta forma entienden que "[...] los Estados Unidos son y han sido diferentes, geográfica, social, política y económicamente", gracias a que, detrás del planteo excepcionalista se esconde "una postura eurocentrista... junto con un profundo debate político-ideológico” (POZZI, 1990, p. 20).

La doctrina del Destino Manifiesto ha de hallarse como fundamento de toda película histórica que muestre, siquiera mínimamente, las relaciones exteriores. Esta mirada del mundo supone que Dios ha determinado que los Estados Unidos de América son el pueblo elegido para la realización del ideal democrático y capitalista, por lo que las decisiones de su política exterior se han de justificar en una concepción religiosa. Los políticos y publicistas que argumentan a favor de esta doctrina sostienen que son tres los temas en los que se fundamentan; a) la importancia y virtud de las instituciones políticas, 
sociales y económicas de los Estados Unidos de América; b) la obligación moral, por parte de los gobernantes del país, de llevar al resto del mundo la excelencia de dichas instituciones; y, c) el hecho de que fuera Dios quien impusiera esa misión, esa "carga de hombre blanco".

La herramienta clave para llevar adelante la postura excepcionalista se encuentra en la Doctrina Monroe. ${ }^{7}$ En consecuencia, con esta base y vinculado al punto a), la expansión norteamericana sobre el resto del mundo establece la frontera en México o El Salvador, pero también en China o Japón. En todos los casos Estados Unidos representa la civilización y la democracia, contra la barbarie y el autoritarismo que expresan sus opositores. Películas tales como 55 días en Pekín ${ }^{8}$ o El Alamo (en cualquiera de sus tres versiones, como se verá más adelante) son una expresión concreta de estas ideas.

Extensivamente, el hombre blanco dentro de los límites del país es un portador de democracia, contra la barbarie de los indios o la estupidez y brutalidad de los negros u orientales. Con base en estos fundamentos aparece el tercer invariante, que es el patriotismo. Todo norteamericano de bien ha de ser buen patriota. Para entender esto deben considerarse los principales elementos que hacen al nacionalismo norteamericano, que se construye de forma diferenciada a los nacionalismos europeos. Sin tener obligatoriamente una religión común, por cuanto las diferentes versiones de interpretación de la biblia daban la posibilidad de desarrollar miradas distintas, la referencia última al cristianismo brindaba un punto de encuentro en un Dios que, gracias a su particular vinculación con los creyentes, marcaba la importancia y diferencia del creyente del norte de América con respecto a los católicos europeos y de la América Latina, tal como claramente estableció Max Weber en su trabajo sobre la íntima vinculación entre el desarrollo del capitalismo y el protestantismo.

Asimismo, el uso del inglés como lengua referente abroquelaba los distintos orígenes políticos, económicos y sociales de los colonos, tras una percepción común del origen. Basándose en los trabajos de Kohn, Dorado indica que el "[...] cimiento principal del nuevo nacionalismo norteamericano era una idea de libertad compartida con la madre patria” (DORADO, 2005, p. 8). El nacionalismo como ideología entronca, necesariamente, con el de la Frontera, que ha sido precedentemente expuesto. 
El cuarto es la recurrencia del conflicto entre el bien y el mal; y ha sido un recurso discursivo de la filmografía histórica norteamericana sistemático y recurrente. Con fundamento en los valores cristianos, donde el bien puede estar claramente representado en los principios y valores de la moral cristiana, ese bien ha de encontrarse normalmente en la prosecución del interés nacional. En líneas generales, lo que hace bien a la grandeza de los Estados Unidos es lo correcto en la película de que se trate. Podría asegurarse con un mínimo margen de error que las películas históricas norteamericanas plantean una identidad entre el interés político coyuntural norteamericano con el bien en su lucha contra el mal. El mal, entonces, es la expresión de valores vinculados a lo que contradice o ataca los intereses que lleva adelante el gobierno de los Estados Unidos en cada etapa histórica.

Es una antinomia simplificada, gracias a la cual el personaje o los personajes centrales (norteamericanos o sus aliados), poseen virtudes humanas y éticas, mientras que los oponentes (japoneses en la década de 1940; soviéticos o comunistas en la de 1950 y hasta la caída del Muro de Berlín; los musulmanes luego), son pérfidos, traidores, sin ningún basamento moral ni ético, brutales, insensibles. Por caso, el Coronel Zaysenen Rambo III'o cualquiera de los somalíes que combaten a los rangers del Ejército norteamericano.

Este elemento es un invariante que tiene múltiples acepciones. Esto es así por cuanto la orientación de cada gobierno no necesariamente persigue los mismos objetivos que su precedente y/o su sucesor. Esto tiene su lógica si se articula con los principiosrectores del Destino Manifiesto y la Frontera. La mirada imperial norteamericana no se inicia sino hasta el momento en que puede darse por cerrada la frontera, para justificar con el concepto de avance hacia el oeste, la expansión colonial-imperialista, es decir, a principios del siglo XX, junto con el desarrollo de la fantástica herramienta de divulgación llamada cine.

Finalmente, el consenso sobre las bondades del sistema norteamericano debe ser pensado como la consecuencia ineludible de los puntos anteriores. Y además como emergente funcional de las necesidades ideológicas de los sectores dominantes de los Estados Unidos, que a tal fin han desarrollado la fórmula historiográfica 
del consenso. Esta perspectiva ha sido determinante en la década de 1950, estableciendo pautas férreas a futuro. Es una escuela historiográfica que debe ser interpretada cuando menos como la sustentadora de la historia oficial, dado que Estados Unidos, dicen sus abogados, "[...] al no tener un pasado feudal, nació libre y sin clases, $\infty$ y era intrínsecamente democrático". Con este basamento, y en un contexto de fuerte presión interna condicionada por la Guerra Fría, el macartismo, y la consolidación de un empresariado vinculado a un Estado Federal Imperial, se aceptó la idea de que los conflictos dentro de la sociedad norteamericana existían, pero siempre con una forma funcional. En suma, "[...] los conflictos en la historia norteamericana son reales pero secundarios, y se generan por las disfuncionalidades que crea el progreso histórico y el desarrollo socio-económico", dijo Hofstadter (POZZI; ELISALDE, 1992, p. 5-7).

Este consenso se configura y reconfigura permanentemente, en función de las necesidades imperiales y empresariales. De esta manera puede verse cómo se ha desarrollado en las décadas de 1950 y 1960 lo que Geoffrey Hodgson ha llamado la Ideología del Consenso Liberal. Según este autor

[...] la ideología contenía dos supuestos fundamentales: que la estructura de la sociedad norteamericana era básicamente sana, y que el comunismo era un peligro palpable para la supervivencia de los Estados Unidos y sus aliados. A partir de estad dos concepciones surgió una visión establecida del país. Esa visión defendía su posición más o menos de esta forma: el sistema económico norteamericano se ha desarrollado morigerando las injusticias y las brutalidades del capitalismo anterior, haciéndose más democrático, y ofreciendo abundancia a una porción mayor de la población. La clave tanto de la democracia como de la abundancia es la producción y el adelanto tecnológico; el crecimiento económico proporciona la oportunidad de estar a la altura de las necesidades sociales, de diluir los conflictos sociales y de hacer que los trabajadores "de cuello azul" (obreros industriales, de la consturcción, textiles, etc.) se incorporen a la clase media (MALAND, 1987, p. 252). 
De esta forma se vuelven menos complejos y explosivos los problemas emergentes de las desigualdades sociales, y por ello se pueden encarar programas específicos para solucionar aquellos emergentes. Sin embargo, la amenaza a este modelo armónico se encuentra en el espectro del comunismo. Entonces, el "mundo libre", conducido por los Estados Unidos "[...] debe prepararse para una larga lucha contra el comunismo y apoyar a conciencia un sistema de defensa poderoso, ya que el poder es el único lenguaje que los comunistas pueden entender" (MALAND, 1987, p. 253). Es por ello que la mayoría de las películas generadas desde Hollywood que refieren o son producto del período se subordinan a la reproducción ideológica de los valores norteamericanos como ideales relevantes de la humanidad misma.

Estos invariantes son los esquemas prototipo sobre los que ha de montarse la trama de un film, porque la historia que interpretamos expresa los sucesos de la narración que organizamos en nuestra mente (BORDWELL; STAIGER; THOMPSON, 1997, p. 12). ${ }^{10}$ Cada escena en estas películas tiene un objetivo histórico y político, con un mensaje claro para cualquier espectador norteamericano. Sin embargo, también resulta importante el aparato cultural que desarrolla, porque más allá de su objetivo interno, con la capacidad económica y política de Hollywood, estas ideas son transmitidas al resto del mundo en donde el mercado fílmico tiene penetración.

Entonces, la percepción y elaboración mental que un espectador construye - particularmente el estadounidense - posee dos niveles. Uno, con base en el sistema de anticipación y formulación de hipótesis que ya trae como bagaje cultural al cine de tipo comercial y, en particular, el clásico de Hollywood, como bien indica Roman Jakobson cuando dice que "[...] en el análisis de las tendencias cinematográficas o de la estructura del filme, es muy importante la necesidad de tener en cuenta la base, los antecedentes de las costumbres del espectador. ¿Qué películas está acostumbrado a ver?” (BORDWELL; STAIGER; THOMPSON, 1997, p. 11). El otro, sobre los invariantes con los que se formó en la escuela y gracias a la memoria mediática, entendida como una mochila construida por el cine a lo largo de los años (CID JURADO, 2007). Avanzando un poco en esta idea, la memoria histórica puede poseer una doble perspectiva: por un lado, se encuentra 
definida desde la construcción ideológica del pasado; por el otro, por las formas de recordarla de cada individuo. De esta manera "[...] los enfoques para abordar el argumento específico (el hecho histórico narrado) varía de acuerdo a la conformación que sufre la memoria institucionalizada y la reconformación del proceso historiográfico" (Ibid., p. 49), lo que permite inferir que habría una relación dialéctica entre la "memoria institucionalizada" y la "reconformación del proceso historiográfico", que implicaría no solo el repreguntarse sobre los hechos, sino también la reconstrucción de las preguntas que se pueden efectuar en términos historiográficos (NIGRA, 2012).

En las películas históricas elaboradas por las Majors (los Grandes Estudios de Hollywood) hay un específico sentido común: un sentido común que se ha venido construyendo desde principios del siglo XX a partir de un aparato ideológico del estado como lo son las instituciones educativas de todos los niveles, las que en su mayoría elaboraron una específica manera de entender y re-construir el pasado, que puede sintetizarse como la historia oficial. Entonces, puede concluirse que lo que ha dado en llamarse la "historia oficial" es una construcción que, de repetida y recirculada, constituye un mecanismo aceptado de forma consensual acerca de la propia Historia. Es lo que se puede decir del pasado, y por ello ha de ser entendida como un discurso social.

Los discursos sociales circulan bajo condiciones determinadas $\mathrm{y}$ también producen efectos bajo condiciones determinadas, y por ello, no puede ser analizado en sí mismo de forma autónoma al contexto de producción en el que surge. Es por estas condiciones que un film sobre un hecho histórico puede rehacerse más de una vez, en parte por ser producto de su época tal como se encarga de repetir Marc Ferro (1995), en parte por la necesidad intertextual que destaca Cid Jurado, que de alguna forma permite hacer aparecer los ecos de la época de filmación, pero también de todas las filmaciones anteriores de esa historia.

Esta construcción social de lo real como producción de sentido se compone de sistemas genéricos, repertorios tópicos, y reglas de encadenamiento de enunciados que en una sociedad organizan lo decible, y aseguran lo que Angenot ha dado en llamar la división del trabajo discursivo (ANGENOT, 2010, p. 21). Para ello este autor 
entiende como lógico tomar la producción social de sentido y la representación social del mundo, a fin de observar todo lo que se dice y escribe en un estado de sociedad, lo que se imprime, habla o representa en los medios. De esta forma, sostiene, puede verse lo que es decible y lo que no en una sociedad determinada. Los discursos sociales son hechos sociales y también hechos históricos, ya que estos discursos tienen eficacia social, y van más allá de las individualidades para ser expresión conceptual del conjunto en el que se inscriben. Por ello, sostiene Angenot que "[...] lo que se enuncia en la vida social acusa estrategias por las que el enunciado 'reconoce' su posicionamiento en la economía discursiva y opera según este reconocimiento, el discurso social, como unidad global, es la resultante de esas estrategias múltiples, aunque no aleatorias" (Ibid., p. 25). ¿No es así en los films históricos que narran hechos heroicos del pasado de la patria?

\section{III}

Trabajaremos algunos ejemplos para analizar los temas aquí desarrollados. Uno es la película El Patriota, del año $2000 .{ }^{11}$ En primer lugar, porque es un film que, al decir de Natalie Davis, es de ambientación histórica en que el argumento y personajes son ficticios, pero su marco histórico es intrínseco a la acción y su significado (ROSENSTONE, 1997, p. 47).

El trasfondo de El Patriota es la guerra de independencia de las Colonias del norte de América. El título del film es claramente indicativo en varios niveles: el de los invariantes (patriotismo, lucha del bien contra el mal, etc.); la independencia como lucha fundacional y constitutiva del ciudadano estadounidense, como la vuelta a las raíces de la patria; la necesidad de hacer un acto de entrega por el supremo valor que es la propia tierra y la propia familia. Para decirlo de otra forma, todos los prototipos, los esquemas mentales que el espectador espera recibir con ese título han de hallarse a lo largo de la película. Es que lo que se cuenta posee con precisión todos los tópicos necesarios para una película histórico-comercial de éxito: la familia, el amor, el heroísmo, el patriotismo. 
La historia se ubica inicialmente en 1776 en Carolina del Sur. El personaje principal se llama Benjamin Martin, que según el autor del guión Robert Rodart, es una "amalgama" libre de varios personajes reales que tuvieron una actuación destacada durante la guerra de independencia (Thomas Sumter, Andrew Pickens, Daniel Morgan, Elijah Dark y Francis Marion), que le proveen al personaje de Martin piezas sustanciales de su carácter. ${ }^{12}$ Este personaje fue, en la historia de la película, un héroe de las guerras Franco-Indias en la época colonial, muy conocido no solamente por sus destacados actos guerreros sino también por la brutal crueldad con la que trató a los vencidos (y que a lo largo de la película es recordado tanto por sus adversarios como por algunos de sus aliados). Ese pasado oscuro lo llevó a pretender una pacífica, apacible y familiar vida de plantación - no debe olvidarse que Carolina del Sur era una zona esclavista -, por lo que al inicio del conflicto con Gran Bretaña se muestra contrario a la participación en la guerra. Esto no es contradictorio, ya que los sureños tenían una relación económica privilegiada con Gran Bretaña, exportando tabaco, añil, arroz y luego algodón. Entonces, que un plantador sureño esté en contra de la guerra es consistente con el personaje.

Debe destacarse que la película es una sumatoria de hechos conectados entre sí por el personaje principal y su confrontación con la representación de la opresión y brutalidad británica, pero en su conjunto es la descripción de varios eventos, que han sido construidos ideológicamente por la historiografía dominante u oficial (asumiendo la idea de que el evento es el hecho bajo descripción). La barbarie y el autoritarismo británicos son la pieza clave por la que el personaje principal cambia su perspectiva; de alguna forma podría decirse que el asesinato de su hijo produce un momento de revelación en Benjamin Martin, ya que gracias a ello puede ver lo que le decían los otros revolucionarios que se habían levantado contra la corona. Es decir, puede pensarse que en el conjunto de hechos mostrados en la filmación se encuentran pocos eventos: la revelación revolucionaria contra la salvaje tiranía; el amor por la familia que es también el amor a la propia tierra, o la patria. La lucha contra la corona explica eventos de los diferentes personajes que hicieron al padre fundador (que nunca existió de verdad) Martin, sus 
sufrimientos, dolores y pesares junto a sus éxitos, pequeños, pero que en la sumatoria conducían a la libertad, como un principio de condensación (en los términos previamente explicados de Rosenstone). Tal vez se propuso en el film la creación de personajes que no adquirieron la relevancia de los Washington, Franklin o Adams, pero que juntos en su objetivo contribuyeron a la construcción de la victoria.

Aquí cabe resaltar que el conjunto de pequeños hechos militares o no, que se muestran en la película, tienen una lógica positivista hollywoodeana, ya que como se destacó más arriba en palabras de Rosenstone, mientras que el decorado, los objetos y las vestimentas sean históricas, tenemos lo que Barthes llamó el efecto de realidad. En pocas palabras, Barthes sostiene que en la literatura realista la acumulación de detalles en la descripción no cumple más que un papel de notación sin una función específica para el relato, más que agregar una información inevitable y sin profundo significado (BARTHES, 1970, p. 95). Entonces, si los detalles denotan directamente lo real, dice, no hacen otra cosa que significarlo, y por ello "[...] la carencia misma de lo significado en provecho solo del referente llega a ser el significado mismo del realismo" (Ibid., p. 100). El positivismo en su formulación tradicional es la descripción de hechos - en algunos casos, que de minúsculos terminan siendo insignificantes en términos históricos -, con lógica causal, inductiva. La película encadena hechos - aún a costa de dar enormes saltos temporales - con lógica de causa-efecto (y aquí corresponde recordar lo sostenido por Bordwell sobre el guión y su necesidad causal), hasta la conclusión final de gloria revolucionaria. Puede decirse que con lógica positivista darwiniana, la humanidad mejora en un salto en calidad hacia la libertad y la democracia (norteamericana, claro está).

En términos de la narración clásica de Hollywood tenemos todos los elementos sustanciales de dicha estructura: un personaje central que es Benjamin Martin presentado en su hecho inalterado de pacífico plantador esclavista sureño (por supuesto, amado por sus esclavos que luchan por él y hasta le reconstruyen su casa sin que lo haya pedido); la alteración de la situación inicial, cuando Tavington asesina a su pequeño hijo; las vicisitudes que hacen a la historia, con algunos éxitos y algunos fracasos, hasta la resolución final. En paralelo, dos historias de amor: la del hijo mayor de Martin con 
una joven de un poblado cercano, que es asesinada por Tavington junto a todo el poblado encerrados en la iglesia que es quemada; y a la vez la de Martin con la hermana de su esposa muerta, que alcanza un final feliz, y de alguna forma se cierra el círculo familiar con un mecanismo que en esa época estaba más que bien visto.

En lo que hace a la estructura técnica de filmación, El Patriota no incorpora ninguna técnica o fórmula que no hubiera sido ya probada (no es Matrix, desde ya), por lo que se mantiene el découpage clásico en el armado; los actores y los escenarios son de lo más representativos de los lugares y las vestimentas que el espectador puede ver, aunque no debe olvidarse que tanto estas vestimentas como el inglés hablado utilizado se apoyan en la idea de facilitar al espectador su introducción en la trama. ${ }^{13}$ La historia contada es bastante simple, repleta de convencionalismos y patrones que disparan los conocimientos prototipo que lleva en su mente el espectador para la construcción de la historia. Finalmente, debe notarse cómo funciona el principio de causalidad, porque en el montaje planteado, en lo que hace a las historias paralelas (las de amor, y las de guerra), un acto concreto se encadena con el siguiente para evolucionar una tras otra hacia la resolución final de cada una de ellas (la del amor heterosexual, la de las batallas).

Otro ejemplo concreto de las ideas expuestas, puede encontrarse en The Green Berets, de John Wayne. Tal como sostiene Dadamo, este film "[...] dadas sus características [...] y el lenguaje al que alude para la transmisión de su mensaje, responde básicamente a la 'fórmula' del western norteamericano que a su vez se encuentra profundamente arraigado en universo social del pueblo estadounidense, tanto como elemento de representación simbólica como componente activamente constitutivo de éste.” (DADAMO, 2010, p. 136-137). Básicamente este tipo de films elaboran relatos sobre "la epopeya sobre el nacimiento de América y la conquista del mítico Oeste” (ROMAGUERA I RAMIÓ, 1999, p. 53), apoyados fundamentalmente en el concepto de frontera antes desarrollado. Según el enorme texto editado por Peter Rollins (ROLLINS, 2003), los westerns se caracterizan por mostrar hombres valientes y masculinos que encarnan los valores de la justicia y la libertad en medio de ambientes hostiles para la concreción de una civilización superadora del salvajismo que los rodea. 
Por lo general, el personaje central de este tipo de películas es un sujeto adámico, un individuo (tanto física como moralmente) de frontera en todo sentido, es el self-mademan norteamericano por excelencia: "está más allá de ese Bien que él sostiene contra el Mal, o tal vez fuera de estas nociones; pertenece a una época sin legislación, a un mundo natural en el que sólo es auténticamente 'malo' aquel que ha sido corrompido por los falsos valores de la sociedad" (ASTRE; HOARAU, 1997, p. 100); o se encuentra por fuera de dicha sociedad, siendo su principal exponente la figura del "el piel roja sediento de sangre". Este enemigo acecha en el ambiente hostil del que él mismo forma parte (el indio es un obstáculo para la conquista de la "tierra prometida"). Sus ataques traicioneros tienen como objetivo tomar desprevenidamente al grupo humano civilizado. Dispuestos a todo y siempre amenazantes son capaces de atacar de noche, dejando un rosario de sus atrocidades que van desde la destrucción material hasta el asesinato de víctimas indefensas. A su vez, vale destacar que las bajas de uno y otro bando la pantalla no se representan de la misma forma. Cuando uno de los "buenos" es asesinado, este acontecimiento adquiere una relevancia de tinte dramático, con detallados primeros planos, o se refuerza con una música acorde a la situación, mientras que los salvajes caen de a montones bajo el fuego justiciero que les propicia una muerte merecidamente anónima y masiva.

The Green Berets ${ }^{14}$ contiene muchos de estos elementos, con la diferencia del color de la piel del enemigo. El gobierno norteamericano tan tempranamente como 1966 necesitaba apoyo, y por ello vió con agrado colaborar con un film que mostrara lo bueno que se estaba haciendo en Vietnam. Entonces, como sostiene Dadamo:

[...] la clave reside en que los componentes característicos del western son compartidos y explotados con claros objetivos propagandísticos, en un film donde se dispara un discurso claro y sin tapujos mientras se tergiversan u omiten sucesos o información sobre la guerra que para 1968 eran ya a todas luces conocidos y repudiados por el público norteamericano (DADAMO, 2010, p. 138). 
La historia de la película establece dos grandes momentos. En el primero, muestra al grupo de boinas verdes comandados por el legendario Coronel Mike Kirby (John Wayne), que deberá brindar apoyo a una base de tropas norteamericanas y vietnamitas aliadas, para luego dar asistencia a una aldea bajo amenaza del VietCong. En el segundo, es un pequeño pelotón comandado nuevamente por Kirby, para llevar adelante una misión secreta, con el objetivo de atrapar al peligroso General Ti, quien tiene bajo su mando las todas las fuerzas guerrilleras del sur de Vietnam.

La estructura y lenguaje de la película responden claramente al modelo de western estadounidense, del cual John Wayne resultó ser un actor emblemático. A esto debe añadirse la utilización del starsystem hollywoodense (detallado por Bordwell), que adquiere relevancia en el protagonista principal, pues si bien este es presentado como el modelo del americanfightingman - una especie de noble caballero moderno que se sacrifica en lucha en pos del progreso, la libertad y los derechos individuales frente a adversarios totalitarios (DOYLE, 2003, p. 567-571) -, sus actitudes y su forma de desplazarse ante las adversidades no dejan de ser las del clásico hombre de frontera que tantas veces había interpretado (DADAMO, 2010, p. 140). Lo que puede observarse en el film (más allá de ciertas inconsistencias al estilo de que los extras y actores enemigos son japoneses y no vietnamitas; o que el trasfondo supuestamente selvático muestra en verdad bosques de pinos) es que el vaquero/soldado se traslada de una frontera semidesértica a una frontera selvática, y "de hecho, la defensa del campamento asignado a los soldados de Estados Unidos tiene una disposición similar a la de un fortín con torres vigías en medio de un claro en lugar de estar camuflada entre la maleza" (Ibid., loc. cit.). Todo refiere más al concepto-patrón, modélico, instalado en la cabeza de los espectadores de la frontera, para que se asuma como natural lo antinatural (retomando así el discurso de naturaleza fílmica del modelo clásico).

Por otro lado, la doctrina del Destino Manifiesto queda por demás expuesta cuando el Coronel Kirby reflexiona sobre la matanza que imparte y la culpa con la que debe cargar, explicando que él solo cumple con "su deber" con la gracia de Dios aunque esta misión le disguste. Como sintetiza Dadamo: 
Los integrantes del VietCong son inhumanos, despiadados y traicioneros. Asaltan por sorpresa, preferentemente de noche y son capaces de todo: tan abominables que matan a mujeres, niños, ancianos que se niegan a colaborar con ellos. Matan por el mero goce que les produce hacerlo y en sus embestidas parece no haber el mínimo respeto o consideración por la vida propia o de sus víctimas. Nuevamente aquí se comprueban el elementos comunes al western clásico: el ataque furtivo y la figura del huérfano inocente que sufre las atrocidades de la contienda en carne propia. También en cuanto a las escenas bélicas y de acción que muestra la película se encuentran paralelismos al representar la muerte y sus diferencias inherentes en ambos bandos. La vida como su final valen más, y copan más minutos de emotividad, en el lado norteamericano que en el vietnamita (DADAMO, 2010, p. 142).

La escena final, con el niño apadrinado por un soldado norteamericano que es muerto en combate, y la frase de John Wayne resume el buscado sentido de carga del hombre blanco asumida por este país. Mientras caminan hacia bello atardecer, en forma paternal el cowboy en el sudeste asiático tranquiliza al pequeño cuando este interroga sobre su futuro: "Tu déjame a mi preocuparme por eso, Boina Verde. Por ti es por lo que es todo esto."

Para finalizar con los ejemplos, puede citarse The Alamo ${ }^{15}$, también dirigida y estelarizada por John Wayne. Los sucesos del Álamo además de formar parte de la memoria nacional como fundacional de la esencia norteamericana, son elementos de una tradición cinematográfica a través de la cual sus hechos se convierten en leyenda. De esta forma, los que lucharon en esa batalla se convierten en héroes y su mensaje se propaga de generación en generación, conformando un universo cinematográfico que se transmite y resignifica constantemente hasta hoy en día. Hay frases como "Recuerden el Álamo", pronunciada por Houston momentos antes de ir a la batalla de San Jacinto, que han quedado grabadas en la historia cinematográfica (PICCINELLI, 2010, p. 70). Esta autora realiza una excelente síntesis de la problemática del film: 
La batalla de El Álamo se establece en la pantalla como un símbolo en donde se expresan casi lineal y proverbialmente los elementos constitutivos de la nacionalidad norteamericana. Ella es esencialmente el emblema de la libertad frente al autoritarismo de los mexicanos, es también sinónimo de la individualidad y la libre empresa frente a las tradiciones atrasadas y corruptas de los españoles. A su vez, al desarrollarse en una zona fronteriza, reproduce en general las características de la tesis turneriana de la frontera. Los hombres anglotexanos frente a la necesidad de defenderse de la opresión española-mexicana, ante la hostilidad de otro que no permite la prosperidad natural - lógica, predestinada - de su vida establecen estrategias de defensa y de lucha por el suelo que consideran suyo. Estas instituciones se revelan esencialmente democráticas, una democracia estadounidense libre de cualquier condicionamiento previo y que nace ante la necesidad de defender lo que se considera propio. La frontera también contribuye a moldear el carácter de los hombres, que si bien responden a distintas facciones y poseen orígenes diversos, a lo largo de la lucha van encontrando un elemento común que los une: la necesidad de ser libres (PICCINELLI, 2010, p. 70-71).

Es más, resulta sintomático que la incorporación de Texas a la Unión, hecho evidentemente planeado cuando se declaró la insurrección contra México, expresa más un hecho ideológico que el que los autores de la revolución contra Santa Anna prefieren reconocer. Como Estados Unidos es la tierra de la libertad, y México el modelo de la tradicional opresión española, el destino de Texas evidentemente estaba en el norte.

En esta película se instala la idea de que esa batalla representan por antonomasia los elementos constitutivos de la nacionalidad norteamericana: el emblema de la libertad contra el autoritarismo, la individualidad y la libre empresa contra los corporativos, brutales y atrasados españoles. Encima la lucha está en la frontera (de México, pero no obsta que sea entendida en sentido general turneriano). Entonces, "[...] la idea del farmer-soldado va cobrando importancia durante el desarrollo de la guerra contra los españoles-mexicanos. Se forman asambleas consultivas de los miembros de los distintos 
pueblos anglo-texanos y ejércitos ad hoc para defender el avance de los mexicanos" (PICCINELLI, 2010, p. 71). Estas prácticas no hacen más que reafirmar el modelo institucional planteado por Frederick Turner, ya que además permite moldear el carácter de los hombres que en la lucha encuentran el común denominador que los vincula: la libertad.

\section{Conclusión}

Las películas de carácter histórico, surgidas de la gran industria hollywoodense, expresan un conjunto de ideas que cumplen varias funciones. En particular desarrollan un juego de "perro que se muerde la cola”, por cuanto refuerzan ideas de tipo hegemónicas y a la vez ayudan al éxito comercial, por ser hegemónicas y encontrarse en el sentido común de los espectadores. Se entiende aquí el concepto de hegemonía tal como indica Portantiero, esto es, una categoría organizacional que se sostiene en el desarrollo de ciertas instituciones, y es una práctica de la lucha ideológica y cultural (PORTANTIERO, 1981, p. 150).

En pocas palabras, el concepto refiere a un proceso gracias al cual una clase social se produce como sujeto histórico, con la capacidad - real o supuesta - de convencer al pueblo o la nación (o sea, las restantes clases sociales como un todo) de que es la conductora del proceso socioeconómico y político. En estas condiciones, dicha clase o fracción de clase elabora un conjunto de herramientas de consenso, a fin de convencer a las otras fracciones de clase, junto a aquellas clases subordinadas, de que los intereses de la dominante son los intereses generales de dicha sociedad. Este último desarrollo es entendido por el autor (quien explicita la oscura escritura de Gramsci) como "acción hegemónica". La acción hegemónica no es solamente una visión ideológica (WILLIAMS, 2000, p. 130-131), por cuanto lo que se busca a través de la acción hegemónica es lograr que grupos que tienen intereses contradictorios a los de los que desarrollan dicha acción, reduzcan la tensión de su propia ideología, para asumir como propios aspectos sustanciales de la ideología dominante. En la acción hegemónica se construyen selectivamente pasados para lograr imaginarios sociales funcionales a la dominación de la fracción de clase dominante. Tal como lo indica Gruppi: 
la hegemonía es esto: capacidad de unificar a través la ideología y de mantener unido un bloque social que, sin embargo, no es homogéneo, sino marcado por propuestas contradictorias de clase. Una clase es hegemónica, dirigente y dominante, mientras con su acción política, ideológica y cultural, logra mantener junto a sí a un grupo de fuerzas heterogéneas, e impide que la contradicción existente entre estas fuerzas estalle, produciendo una crisis en la ideología dominante y conduciendo a su rechazo, el que coincide con la crisis política de la fuerza que está en el poder (GRUPPI, 1978, p. 95).

La utilización de un pasado consensual a través de un medio masivo de comunicación como lo es el cine, gracias a la aplicación de principios sustanciales de la historia oficial actuando en conjunto con grandes capitales, da como resultado no solamente una gran posibilidad de éxito comercial sino también de ratificación de los principios ideológicos funcionales a la clase dominante. A tal fin se desarrollaron técnicas de narración histórica y fílmica probadamente eficaces (el sistema clásico), los que se apoyan en ideas que refuerzan ideas dominantes. En suma, para decirlo en pocas palabras, el cine histórico de Hollywood como acción hegemónica.

\section{O CINEMA HISTÓRICO DE HOLLYWOOD COMO AÇÃO HEGEMÔNICA}

Resumo: Este artigo se insere em um trabalho maior que analisa as particularidades da narrativa fílmica de filmes históricos produzidos pelos grandes estúdios de Hollywood. Para tanto, são inicialmente discutidas linhas teóricas, como as de Ferro e de Rosenstone, para definir uma abordagem própria. A seguir, trata-se da fórmula historiográfica e fílmica que caracteriza tais filmes, e são apresentados exemplos. Na conclusão, pretende-se demonstrar que a grande maioria dessas produções tem seu fundamento em questões culturais e ideológicas que não só garantem sucesso comercial como também reforçam princípios ideológicos da classe dominante.

Palavras-chave: Estados Unidos. Cinema Histórico. Hegemonia. 


\section{Notas}

${ }^{1}$ Braveheart (Corazón Valiente), 1995, con la dirección de Mel Gibson y guión de Randall Wallace.

${ }^{2}$ La noche de los lápices (1986), con la dirección de Héctor Olivera y guión de Daniel Kon.

${ }^{3}$ Howthewestwas won (La conquista del oeste), 1962, con la dirección de varios directores, como John Ford, Henry Hathaway, George Marshall y Richard Thorpe; guión de John Gay y James R. Webb; con la actuación de Caroll Baker, Lee J. Cobb, Henry Fonda, Karl Malden, John Wayne, Gregory Peck, George Peppard, James Stewart, Richard Widmark, entre muchos otros. El texto original se basó en una serie de notas efectuadas por la Revista Life.

${ }^{4}$ En la entrevista realizada por Mario Ranalletti a Robert Rosenstone, éste afirmó: "Pero Ferro no hace lo que yo hago: examinar la validez de los filmes como una escritura de la historia, en relación al modo en que los historiadores han escrito historia. Para Ferro, las películas sólo parecen reflejar el pasado. Esto es verdad, pero los filmes pueden ser una manera de hablar acerca del significado del pasado, también.” En Entrepasados, año 8, n. 15, p. 14, 1998.

${ }^{5} \mathrm{Al}$ producirse en las postrimerías del siglo XX la ruptura de los "grandes relatos de legitimación" (liberalismo, marxismo, pero también cualquier otro que englobara descripciones totalizadoras de procesos o problemas).

${ }^{6}$ Northwestpassage (Pasaje al noroeste), 1940, dirigida por King Vidor; con la actuación de Spencer Tracy, Robert Young y Walter Brennan entre otros.

${ }^{7}$ La Doctrina Monroe, elaborada por el mismo presidente Monroe "[...] fue declarada en el último mensaje presidencial al Congreso, en diciembre de 1823. Afirmó que los continentes americanos ya no estaban abiertos a la colonización por potencias europeas y formuló una advertencia contra cualquier intervención europea en las nuevas naciones revolucionarias de América latina y contra la extensión de sistemas políticos europeos en las Américas. Expresión de un nacionalismo que tenía confianza en sí mismo, la declaración unilateral de Monroe reconoció la existencia de esferas de influencia y, por inferencia, reinvindicó una de ellas en América latina para los Estados Unidos”. En SELLIERS; MAY; MCMILLAN. Sinópsis de la historia de los Estados Unidos. Buenos Aires: Editorial Fraterna, 1988. p. 181. También puede consultarse MOYANO PAHISSA; VELASCO MARQUEZ. EUA. Documentos de su Historia Política I. Mexico: Instituto Mora, 1988. p. 387-397. 
855 Days at Peking (55 días en Pekín), 1963, con la dirección de Nicholas Ray, y protagonizada por Charlton Heston, Ava Gadner y David Niven entre otros. ${ }^{9}$ Rambo III, 1988, dirigida por Peter McDonald y protagonizada por Sylvester Stallone y Richard Crenna principalmente.

${ }^{10}$ Como lo discrimina Bordwell: "Los formalistas rusos distinguían entre fábula ('historia') y syuzhet ('trama'), y a lo largo de este libro utilizaremos la distinción entre historia y trama en un sentido similar al de los formalistas. 'Historia' hará referencia a los sucesos de la narración en sus supuestas relaciones espaciales, temporales y causales. 'Trama' hará referencia a la totalidad de los materiales formales y estilísticos de la película. De este modo, la trama incluye todos los sistemas de tiempo, espacio y causalidad que, de hecho, se manifiestan en la película, desde la estructura de un flashback y el punto de vista subjetivo a los más pequeños detalles de la iluminación, el montaje y los movimientos de cámara. La trama es, en efecto, la película que tenemos ante nosotros. La historia es, por tanto, nuestra construcción mental, una estructura de inferencias que hacemos según aspectos seleccionados por la trama."

${ }^{11}$ The Patriot (El patriota), 2000, dirigida por Roland Emmerich, y protagonizada por Mel Gibson, Heath Ledger y Joely Richardson, entre otros.

${ }^{12}$ Tomado de <http://cinema.com/articles/204/patriot-the-production-notes. phtml>, en 16/02/2014.

${ }^{13}$ Facilitador es un concepto que se desarrolla en el capítulo "Trasposición y cine histórico”, en NIGRA, F. Historias de Cine. Valencia: PUV, 2013. p. 126. En pocas palabras, el concepto de facilitador intenta justificar los anacronismos diversos que aparecen en las películas históricas, como el uso del idioma moderno y no el que se utilizaba en la época de la película; o la ropa que no es una copia exacta de la utilizada, sino que tiene toques más moderno y accesibles a la vista y/o comprensión del espectador.

${ }^{14}$ The Green Berets (Los Boinas Verdes), 1968, dirigida por Ray Kellogg y John Wayne, y protagonizada por el mismo Wayne, junto a David Janssen, Jim Hutton y otros.

${ }^{15}$ The Alamo (El Álamo), 1960, dirigida por John Wayne, quien también la protagoniza, junto a Richard Widmark, Laurence Harvey y otros.

Anos 90, Porto Alegre, v. 22, n. 42, p. 375-405, dez. 2015 


\section{Referencias}

ANGENOT, M. El discurso social: los límites históricos de lo pensable y lo decible. Buenos Aires: Siglo XXI, 2010.

ASTRE, G.A.; HOARAU, A. P. El universo del Western. España: Editorial Fundamentos, 1997.

AUGROS, J. El dinero de Hollywood: financiación, producción, distribución y nuevos mercados. Barcelona: Paidós, 2000.

AUMONT, J.; BERGALA, A.; MARIE, M.; VERNET, M. Estética del cine: Espacio fílmico, montaje, narración, lenguaje. Buenos Aires: Paidós, 2011.

BARTHES, R. El efecto de realidad, en AAVV, Lo verosímil, Buenos Aires: Ed. Tiempo Contemporáneo, 1970, p. 95. Se ha reproducido en BARTHES, R. El susurro del lenguaje. Barcelona: Ed. Paidós, 1987.

BORDWELL, D. El estilo clásico de Hollywood, 1917-1960. En: BORDWELL, D.; STAIGER, J.; THOMPSON, K. El cine clásico de Hollywood: estilo cinematográfico y modo de producción hasta 1960. Barcelona: Paidós, 1997.

BORDWELL, D. La narración en el cine de ficción. Barcelona: Paidós, 1996.

CID JURADO, A.T. El desembarco de Normandía y el imaginario cinematográfico: del hecho fílmico a la reconstrucción del hecho histórico. Semióticas del Cine, Maracaibo, n. 5, 2007.

COLLINGWODD, R. Idea de la Historia. México: FCE, 2001.

DADAMO, F. Vietnam: La nueva "frontera" de John Wayne. En: NIGRA, F (Coord.). Hollywood, ideología y consenso en la historia de Estados Unidos. Ituzaingó: Maipue, 2010.

DORADO, A. Los fundamentos del nacionalismo norteamericano: la construcción de una nación. Ponencia presentada en: LAS XMAS. JORNADAS INTERESCUELAS-DEPARTAMENTOS DE HISTORIA, 20-23 de septiembre de 2005.

DOYL, R. C. The American fighting Man. En: ROLLINS, P. (Ed.). The Columbia companion to American history on film: how the movies have portrayed the American past. New York: Columbia University Press, 2003.

FERRO, M. Historia Contemporánea y Cine. Barcelona: Ariel, 1995. 
El cine histórico de Hollywood como acción hegemónica

GONZALEZ PASCUAL, A. Ideología en el cine estadounidense (1990-2003). Madrid: Fundamentos, 2010.

GRUPPI, L. El concepto de hegemonía en Gramsci. México: Ediciones de Cultura Popular, 1978.

MALAND, CH. Doctor Strangelove: Comedia de pesadilla e ideología del consenso liberal. En: ROLLINS, P (comp.). Hollywood: El cine como fuente histórica: La cinematografía en el contexto social, político y cultural. Buenos Aires: Fraterna, 1987.

MILLER, T. El nuevo Hollywood. Barcelona: Paidós, 2005.

MONTERDE, J. E. Cine, historia y enseñanza, Barcelona: Laia, 1986.

MOYANO PAHISSA, A.; VELASCO MARQUEZ, J. EUA: Documentos de su Historia Política I. México: Instituto Mora, 1988.

NIGRA, F (Comp.). El discurso histórico en el cine de Hollywood. Buenos Aires: Imago Mundi, 2014.

. Historias de Cine: Hollywood y Estados Unidos. Valencia: PUV, 2013.

. Hollywood y la historia de Estados Unidos: la fórmula estadounidense para contar su pasado. Buenos Aires: Imago Mundi, 2012.

. (Coord.). Hollywood, ideología y consenso en la historia de Estados Unidos. Ituzaingó: Maipue, 2010.

. Notas sobre la memoria mediática y discurso social en el cine histórico de Hollywood. Ponencia presentada en: III CONGRESO INTERNACIONAL DE LA ASOCIACIÓN ARGENTINA DE ESTUDIOS DE CINE Y AUDIOVISUAL (AsAECA-Eje 4 Mesa 4A), Córdoba, mayo de 2012.

. Sobre la historia norteamericana, versión Hollywood: algunas hipótesis de trabajo. Siembra, Chapingo, año 3, n. 7, mayo/agosto de 2007.

PICCINELLI, M. La historia que nos cuenta el cine: El Álamo y la reedición de la doctrina del Destino Manifiesto en el siglo XXI. En: NIGRA, F (Coord.). Hollywood, ideología y consenso en la historia de Estados Unidos. Ituzaingó: Maipue, 2010.

PORTANTIERO, J.C. Los usos de Gramsci. México: Folios, 1981.

POZZI, P.; ELISALDE, R. Conflicto y consenso en la historiografía norteamericana: una historia politizada. En: POZZI, P. et al. Un pasado imperfecto: Historia de Estados Unidos. Buenos Aires: Manuel Suárez Editor, 1992.

. Excepcionalismo y Clase Obrera en los Estados Unidos. En: POZZI, P. et al. De Washington a Reagan: Trabajadores y Conciencia de Clase en los Estados Unidos. Buenos Aires: Cántaro, 1990.

Anos 90, Porto Alegre, v. 22, n. 42, p. 375-405, dez. 2015 
ROBB, D. Operación Hollywood: La censura del Pentágono. Barcelona: Océano, 2006.

ROLLINS, P (Ed.) The Columbia companion to American history on film: How the movies have portrayed the American past. New York: Columbia University Press, 2003.

ROMAGUERA I RAMIÓ, J. El lenguaje cinematográfico: gramática, géneros, estilos y materiales. Madrid: Ediciones de la Torre, 1999.

ROSENSTONE, R. El pasado en imágenes: el desafío del cine a nuestra idea de la Historia. Barcelona: Ariel, 1997.

SANCHEZ RUIZ, E. E. Hollywood y su hegemonía planetaria: una aproximación histórico-estructural. Guadalajara, México: Universidad de Guadalajara, 2003. La Colección de Babel, n. 28.

SELLIERS, Ch.; MAY, H.; MCMILLAN, N. Sinópsis de la historia de los Estados Unidos. Buenos Aires: Editorial Fraterna, 1988.

TURNER, F. J. La frontera en la historia americana. Madrid: Editorial Castilla, 1961.

VERON, E. La semiosis social: Fragmentos de una teoría de la discursividad. Buenos Aires: Gedisa, 1998.

WHITE, H. Metahistoria: La imaginación histórica en la Europa del siglo XIX. México: FCE, 1992. Primera edición en inglés de 1973.

. Narrativa histórica y narrativa ideológica. En: La ficción de la narrativa: ensayos sobre historia, literatura y teoría, 1957-2007. Buenos Aires: Eterna Cadencia, 2011.

WILLIAMS, R. Marxismo y Literatura. Buenos Aires: Península, 2000.

XAVIER, I. El discurso cinematográfico: la opacidad y la transparencia. Buenos Aires: Manantial, 2008.

Recebido em: 25/11/2014

Aprovado em: 05/03/2015 